\title{
Resumos de
}

\section{Teses Homologadas}

Janeiro-Abril/2020 


\section{DANIELA DUARTE DA SILVA BAGATINI}

Orientador: Prof. a Dr. a Maria Cristina Villanova Biasuz

Data: $29 / 01 / 2020$

Local: Sala 329 - Auditório do PPGIE/CINTED

Tese: "Navegar é Preciso": o Continuum Experiencial de Programação com a Web

Resumo: Esta tese tem por objetivo compreender a valorização da busca na Web e as implicações dessa experiência para estudantes universitários de Computação na resolução de problemas de programação. A partir da percepção de experiência revelada no cenário da prática de programação apoiada pela Web, desdobra-se esta pesquisa em dois caminhos investigativos: a ação do estudante e a operação do meio. O entendimento da disponibilidade da solução de programação mobiliza a discussão da cópia, já o ambiente compelidor da Web põe em pauta o processo da busca. O percurso realizado pela tese começa em Buscando o lugar da experiência, onde apresentamos a preocupação inicial a partir da fala de um estudante - "Se não está na Internet, não existe" - no contexto da disciplina de Estrutura de Dados. Como trabalho científico, analisamos estudos relacionados que discutem o plágio do código-fonte e o efeito descalibrado do próprio conhecimento promovido pelo acesso a Web. Em continuação, realizamos a aproximação da preocupação inicial com a teoria defendida por John Dewey para formular o entendimento de experiência e discutir os Princípios de Continuidade e de Interação. Também trazemos para a discussão Jorge Larrosa, Alberto Cupani, Marshall McLuhan e William Powers. No andamento, problematizamos o objeto da pesquisa e as condições do contexto Web, reafirmamos a necessidade de pensá-lo como algo a refletir e considerar. Em Buscando significados, apresentamos o quadro metodológico que inclui os dados de um questionário quantitativo aplicado com estudantes universitários ( $n=149$ respostas), o qual fornece indícios sobre a valorização da experiência com a Web sustentada na importância, satisfação e indispensabilidade que atribuem ao meio. Os resultados são aprofundados na etapa qualitativa, onde é possível perceber as implicações da relação com o meio nas entrevistas com estudantes que participaram de atividades de desafios de programação. Assim, conduzimos a tese, no sentido de uma concepção autêntica de que navegar é preciso, mas que também é necessário estar atento à situação de cada experiência, pois serve de instrumento para promover o continuum experiencial. Observamos que os estudantes entendem sua experiência com a Web como positiva e são cientes das boas e más implicações. Porém, ao contrário do que pensávamos em nosso pressuposto, os estudantes abrem mão de parte da consciência crítica e do desenvolvimento educativo da experiência, por vantagens que caracterizam um agir essencialmente tecnológico no tempo, nos protocolos e nos hábitos.

Palavras-chave: Experiência. Estrutura de Dados. Programação. Web. 


\section{ELISA FRIEDRICH MARTINS}

Orientador: Prof. Dr. Marcus Vinícius de Azevedo Basso

Data: 09/01/2020

Local: Sala 329 - Auditório do PPGIE/CINTED

Tese: Pensamento Combinatório e Objetos Digitais de Aprendizagem: Estudo Construtivista nos Anos Iniciais

Resumo: A presente pesquisa busca compreender o desenvolvimento do pensamento combinatório em crianças dos anos inicias do Ensino Fundamental. Para isso, mostrou-se necessário conceber e desenvolver um Objeto Digital de Aprendizagem (ODA) abordando o tema voltado para essa faixa etária. A concepção, assim como a utilização do objeto produzido foram realizados sob a perspectiva do construtivismo de Jean Piaget. $O$ desenvolvimento do ODA se deu com base no que indica a bibliografia sobre requisitos pedagógicos e técnicos. $O$ uso do ODA fez parte da produção de dados da pesquisa. A análise das resoluções dos problemas apresentados e dos caminhos percorridos pelos estudantes na busca pelas soluções tornaram-se objetos de análise para que se pudesse esclarecer como o pensamento combinatório se desenvolve no estádio das operações concretas.

Palavras-chave: Objetos de Aprendizagem; Pensamento Combinatório; Construção de conhecimento 


\section{VALTER ANTONIO FERREIRA}

Orientador: Prof. a Dr. a Liane M. Rockenbach Tarouco

Coorientador: Prof. Dr. Fernando Becker

Data: $07 / 01 / 2020$

Local: Sala 329 - Auditório do PPGIE/CINTED

Tese: Laboratórios Virtuais Imersivos 3D Processos Cognitivos em Experimentos de Eletromagnetismo

Resumo: Este trabalho investigou o esforço cognitivo de estudantes universitários durante simulações computacionais de experimentos virtuais imersivos 3D de Eletromagnetismo, desenvolvidos na plataforma OpenSim. Os experimentos foram desenvolvidos com base em situações de equilíbrio físico, utilizando conceitos como atração e repulsão magnéticas, geração de campo magnético por corrente elétrica e teoria de circuitos elétricos. A Epistemologia Genética de Piaget foi empregada como fundamentação teórica para o estudo, fornecendo parâmetros tanto para as estratégias de criação dos experimentos quanto para a obtenção e análise dos dados advindos das entrevistas clínicas. Ao longo das simulações, os diálogos ocorreram com base em protocolos previamente desenvolvidos para seguir o pensamento dos sujeitos, sendo gravados em áudio. As manipulações experimentais tiveram a tela do computador capturada em formato de vídeo usando o programa CamScanner. A análise das informações coletadas verificou a existência de esforço cognitivo através de elementos como criação e comprovação de hipóteses, abstrações reflexionantes: pseudo-empíricas e refletidas, realização de coordenações causais e inferenciais.

Palavras-chave: Laboratório Virtuais Imersivos 3D; Epistemologia Genética; Ensino de Física; 